\title{
Permanent Fault Location in Distribution System Using Phasor Measurement Units (PMU) in Phase Domain
}

\author{
Ali Khaleghi ${ }^{1}$, Mahmoud Oukati Sadegh ${ }^{2}$, Mahdi Ghazizadeh Ahsaee ${ }^{3}$ \\ ${ }^{1}$ University of Sistan and Baluchestan, Iran \\ ${ }^{2,3}$ University of Zabol, Iran
}

\begin{tabular}{l} 
Article Info \\
\hline Article history: \\
Received Oct 1, 2017 \\
Revised Jan 11, 2018 \\
Accepted July 27, 2018 \\
\hline
\end{tabular}

Keywords:

Distributed-parameter

line model

Fault location

Permanent fault

Phasor measurement units

\begin{abstract}
This paper proposes a new method for locating high impedance fault in distribution systems using phasor measurement units (PMUs) installed at certain locations of the system. To implement this algorithm, at first a new method is suggested for the placement of PMUs. Taking information from the units, voltage and current of the entire distribution system are calculated. Then, the two buses in which the fault has been occurred is determined, and location and type of the fault are identified. The main characteristics of the proposed method are: the use of distributed parameter line model in phase domain, considering the presence of literals, and high precision in calculating the high impedance fault location. The results obtained from simulations in EMTP-RV and MATLAB software indicate high accuracy and independence of the proposed method from the fault type, fault location and fault resistance compared to previous methods, so that the maximum observed error was less than $0.15 \%$.
\end{abstract}

Copyright (c) 2018 Institute of Advanced Engineering and Science. All rights reserved.

\section{Corresponding Author:}

Mahmoud Oukati Sadegh,

Department of Electrical and Electronic Engineering,

University of Sistan and Baluchestan, Zahedan, Iran.

Email: oukati@ece.usb.ac.ir

\section{INTRODUCTION}

Each distribution system has many literals, load taps, balanced and non-balanced loads, and different types of conductors, which complicate the calculation of fault location in this system. Many studies have been done to locate faults in distribution systems [1]-[5]. In [1], short line model and phase components were used for locating. The sensitivity of this method to the fault resistance is high. In [2]-[4], the distributed parameter line model and the main component of voltage and current are used. In These articles the presence of literals has not been considered. In [5], the distributed parameter line model has been used for a singlephase-to-ground fault, but the existence of literals and unbalanced performance of the network have not been analysed.

Permanent high impedance faults in distribution networks are generally due to their low level of voltage. The low voltage of the distribution network and high ground resistance cause low fault current in this type of faults. Therefore, protections in the network, such as distance or overcurrent relays, will not be able to identify them [6]. These types of faults generally occur in two ways, such that the conductor contacts a high impedance object, such as branches of the tree, or the conductor is cut off on the ground [7]. To date, most of the work in the distribution system has been limited to detecting high impedance faults, these include the use of numerical fault analysis [8], neural network [9] and the presentation of a wavelet transform algorithm [10]. Regarding the location of high impedance fault in the distribution system, one can refer to the use of wavelet transform in [11]. Since it is impossible to ignore the capacitive effect of the line during the fault in the distribution system, modeling this effect is very important for having high accuracy in obtaining the fault location. In recent years with the development of telecommunication systems, phasor measurement 
units (PMU) have changed to one of the most important systems for Wide Area Monitoring, Protection and Control (WAMPC) of power systems [12]-[14]. These equipment, using strong signal processing technology and a global positioning system (GPS), enables to simultaneously calculate the voltage and current of the branches on which the PMU is installed [15]. In [16] and [17], PMU placement in the distribution network is proposed to estimate the network state, and furthermore, this technology is used in fault locating of power systems [18]-[20].

In this paper, considering the importance of the capacitive effect of line, an algorithm is proposed to improve the accuracy of impedance-based fault locating methods, using the distributed parameter line model in phase domain, which, contrary to previous methods [1]-[6], has lower sensitivity to resistance, location and type of the fault. In the proposed method, using phasor measurement units installed in the distribution system, voltage and current of all parts of the distribution system is calculated. Then, two buses where the fault occurred in the line between them is determined and with the other calculations, the fault location is computed. The proposed method is evaluated on $25 \mathrm{kV}$ network (Saskpower) in Canada [21] in the presence of literals and static loads. The results showed high accuracy of the algorithm.

In the remaining of the paper, the second part describes the proposed method for calculating the fault location and determining the type of fault in the line in which the error occurred. The third section describes the PMUs placement and how to apply the proposed method to the distribution networks. In the fourth section, the simulations and the results for the evaluation of the proposed method have been investigated and, finally, a conclusion has been made.

\section{PROPOSED METHOD}

\subsection{Fault classification}

In this section, considering the distributed parameter line model in the phase-domain and using impedance-based method, the article sets to calculate the fault location, type (phase-to-phase and phase-toground) and resistance. One section with $\Delta \mathrm{x}$ length of the line can be shown in Figure 1 . According to Figure 1, the Equation 1 can be written as follows:

$$
\begin{aligned}
& \frac{V}{x}=z I \\
& \frac{I}{x}=y V
\end{aligned}
$$

where: $\Delta \mathrm{V}$ : Voltage drop on series impedance of elemental length of the line

$\Delta \mathrm{I}$ : Capacitance current of elemental length of the line

$\mathrm{z}$ : series impedance matrix of the line per $\mathrm{km}$ $\mathrm{y}$ : shunt admittance matrix of the line per $\mathrm{km}$

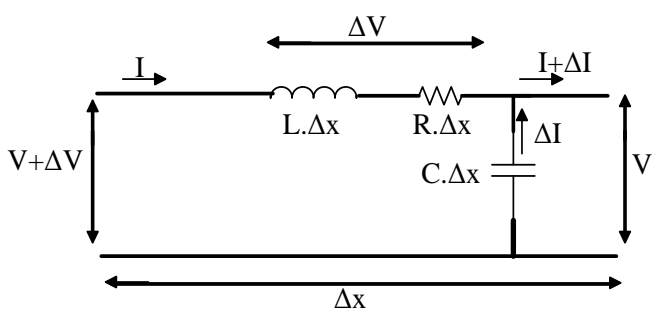

Figure 1. Elemental section of line with length of $\Delta \mathrm{x}$

The differentiation of Equation 1 with respect to $x$ leads to Equation 2. In power lines, phases mutually affect each other due to mutual coupling. Using the method of symmetrical components (matrix (3)), independent phase components and Equations 4 and 5 can be obtained:

$$
\begin{aligned}
& \frac{2_{V}}{x^{2}}=z y V \\
& \frac{2_{I}}{x^{2}}=y z I
\end{aligned}
$$




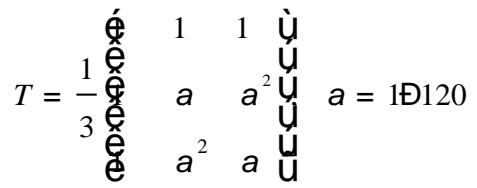

$$
\begin{aligned}
& \frac{{ }^{2} V_{0,+,-}}{x^{2}}=T z y T^{-1} V_{0,+,-} \\
& \frac{{ }^{2} I_{0,+,-}}{x^{2}}=T y z T^{-1} I_{0,+,-}
\end{aligned}
$$

Solving Equations 4 and 5 and using Equation 6, the sequence of the voltage and current of each section can be calculated. $K$ represents the sequences of positive, negative and zero.

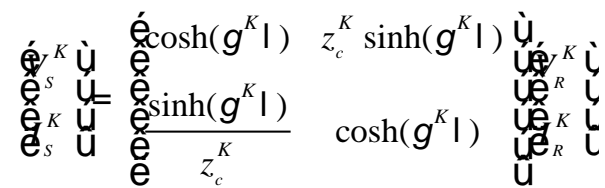

g, $\mathrm{z}_{\text {с }}$ Are defined as follows:

$$
\begin{aligned}
& g^{k}=\sqrt{z^{k} y^{k}} \\
& z_{c}^{k}=\sqrt{\frac{z^{k}}{y^{k}}}
\end{aligned}
$$

where: $l$ : the total length of section

$V R$ : voltage of end bus of section

$I R$ : current that is inputted to end bus of section

As will show in subsection 3.2, using phasor measurement units installed in the distribution system, the voltage and current of the two $\mathrm{S}$ and R buses, the fault occurred between them, can be calculated. In Figure 2 Using Equations 7 and 8, the voltage and current on the two sides of the fault point can be obtained.

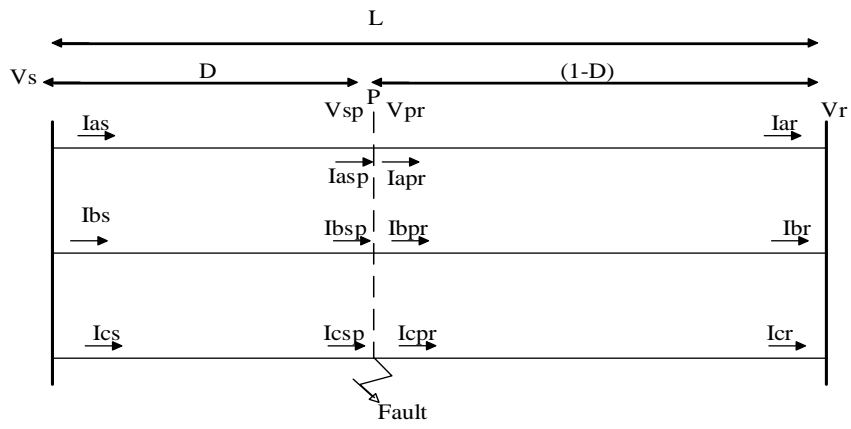

Figure 2. Line between $\mathrm{S}$ and $\mathrm{R}$ buses that fault is occurred

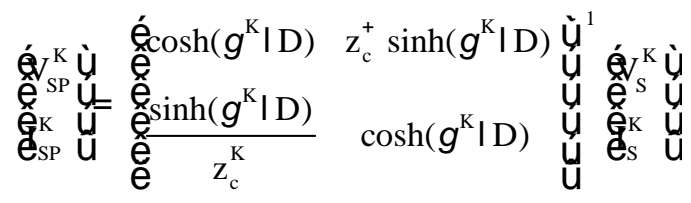

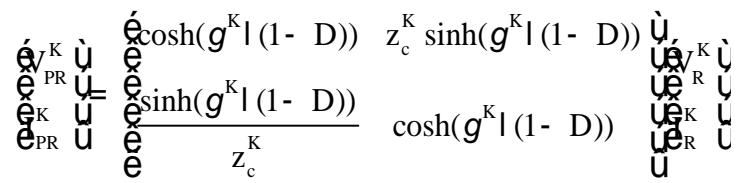


where: $V_{s p}^{k}$ : Voltage of fault point from sending side

$V_{p r}^{k}$ : Voltage of fault point from receiving side

$I_{s p}^{k}$ : Current of fault point from sending side

$I_{p r}^{k}$ : Current of fault point from receiving side

Since the voltage is equal at the point of fault, the following equations can be written:

$$
\begin{aligned}
& V_{P R}^{-}=V_{S P}^{-} \\
& V_{P R}^{0}=V_{S P}^{0} \\
& V_{P R}^{+}=V_{S P}^{+}
\end{aligned}
$$

The only unknown factor in the above equations is the fault location per line length unit (D) that can be obtained through solving Equations 9, 10 and 11 using Newton-Raphson algorithm. When the network is in the form of single-phase lines, instead of Equation 6, the following equation is used:

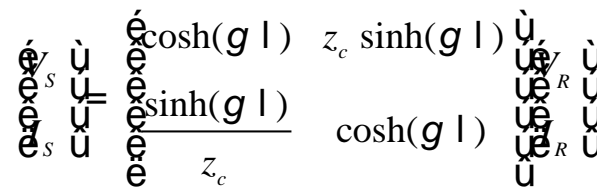

In the next sub-section, the fault type detection method in the two groups of phase-to-phase and phase-to-ground is separately determined and the fault resistance will be calculated.

\subsection{Fault Type Determination and Fault Resistance Calculation}

To determining the type of fault, using transfer matrix and according to the equations 13 and 14 the phase voltage and current at the point of fault can be estimated:
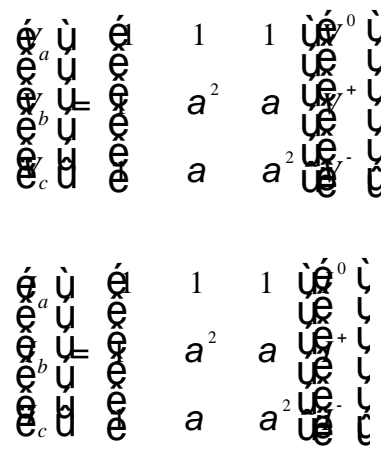

\subsubsection{Phase to Phase Fault}

For example, the phase to phase fault for A and B phases by impedance fault ZFab is shown in Figure 3. The fault current can be obtained as follows:

$$
\begin{aligned}
& I_{F a}=I_{\text {asend }}-I_{\text {a receive }} \\
& I_{F b}=I_{b \text { send }}-I_{b \text { receive }} \\
& I_{F c}=I_{c \text { send }}-I_{c \text { receive }}
\end{aligned}
$$


If one of the equations 18,19 and 20 holds true, there is phase to phase fault:

$$
\begin{aligned}
& I_{F a}=-I_{F b} \\
& I_{F a}=-I_{F c} \\
& I_{F b}=-I_{F c}
\end{aligned}
$$

AB impedance phase-to-phase fault is calculated from the equation 21.

$$
Z_{F a b}=\frac{V_{F a}-V_{F b}}{I_{F a}}
$$

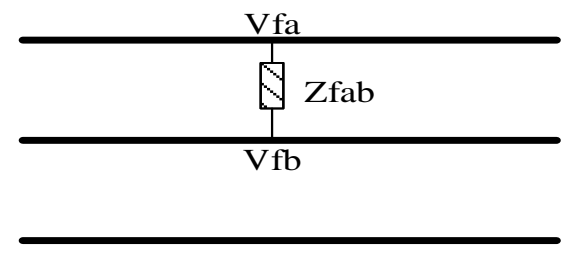

Figure 3. Phase to phase fault model

\subsubsection{Phase to Ground Fault}

If Equations 18, 19 and 20 do not confirm, it can be concluded that a phase to ground fault has been occurred. This fault is modelled as shown in Figure 4. The fault impedance matrix can be written like equation 22:

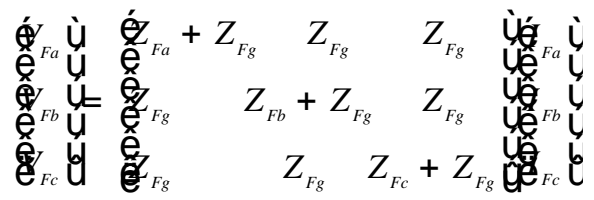

As a result, due to the fact that the phase voltage and current of the fault point are known, the impedance matrix can be calculated and according to the values obtained for the fault impedance of equation 22 and the fault current, one can determine which types of faults (Single-phase to ground, two-phase to ground and three-phase to ground) occurred in the distribution system.

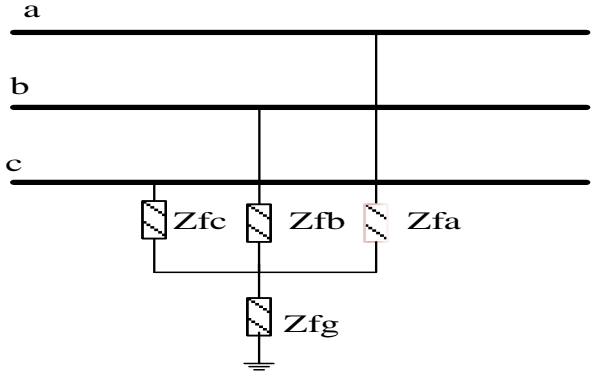

Figure 4. Phase to ground fault model 


\section{IMPLEMENTATION OF THE PROPOSED METHOD ON DISTRIBUTION SYSTEMS}

The proposed method for fault location is based on assumption that the voltage and current of the two buses in which the fault occurred in the line between them are known. However, only the voltage and current of a limited number of buses on which PMUs are installed are available. Therefore, in the rest of the article, a method for PMUs placement with respect to the proposed algorithm is presented to obtain the data of other buses through using the PMUs data.

\subsection{PMU Allocation in Distribution Systems}

\subsubsection{Network Observability Using PMU}

PMU installed on a specific bus can measure the voltage magnitude and phase angle of bus as well as the magnitude and phase angle of branches currents attached to that bus. As a result, the magnitude and phase angle of voltage and current of buses connected to the bus that equipped with PMU can also be estimated using basic rules (KVL, KCL) of electricity. Consider, for example, Figure 5, the buses in which the PMU is installed (PMU buses) are direct observable, and those buses that are connected to the PMU buses are indirect observable. The others are not observable [22-23].

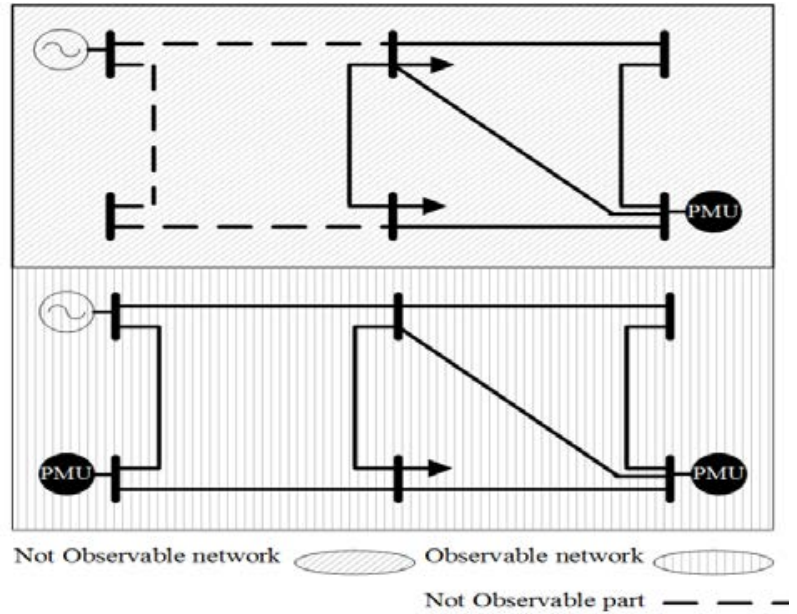

Figure 5. Network observability using PMU

\subsubsection{PMU Allocation Algorithm}

PMU placement should provide the following conditions:

a. According to the placement of PMUs the voltage and current of all buses from two sides can be calculated. This means that when fault is occurred in one side of a bus, the data of bus can be acquired from the other side that is intact (completely observability).

b. In all buses not connected from one side to the other bus (end buses), a PMU is installed so that information is available in the event of a fault on the other side of the end bus.

After allocating PMUs with considering above conditions, the voltage and current of all buses can be calculated at any time.

\subsection{Feeder's Data Calculation}

To better explain the contents of this subdivision, for example, a single-line diagram of a sample distribution system is shown in Figure 6. According to PMU placement algorithm the PMUs are installed on buses $1,5,6$. Therefore, the voltage and current of these buses will be simultaneously and directly available for fault locator. The calculation of the voltage and current of buses 2 and 4 in the normal mode of the network will be as follows:

It is assumed that loads in the buses where PMU is not installed are static. From bus 6, using Equation 6, voltage and current $I_{46 a b c}, V_{4 a b c}$ can be obtained. Therefore $I_{42 a b c}$ can be calculated using Equation 23: 


$$
I_{42 a b c}=I_{46 a b c}+\frac{V_{4 a b c}}{Z_{L 4}}
$$

From the bus 1, the $I_{21 a b c}, V_{2 a b c}$ and from bus $5, I_{35 a b c}, V_{3 a b c}$ are estimated according to equation 6 and then $I_{32 a b c}$ is obtained via (24):

$$
I_{32 a b c}=I_{35 a b c}+\frac{V_{3 a b c}}{Z_{L 3}}
$$

According to equation 6 and the obtained $V_{3 a b c}, I_{32 a b c}$, the current $I_{23 a b c}$ is estimated, and:

$$
I_{24 a b c}=I_{21 a b c}-I_{23 a b c}-\frac{V_{2 a b c}}{Z_{L 2}}
$$

Thus, $V_{4 a b c}, V_{2 a b c}, I_{42 a b c}, I_{24 a b c}$ are known.

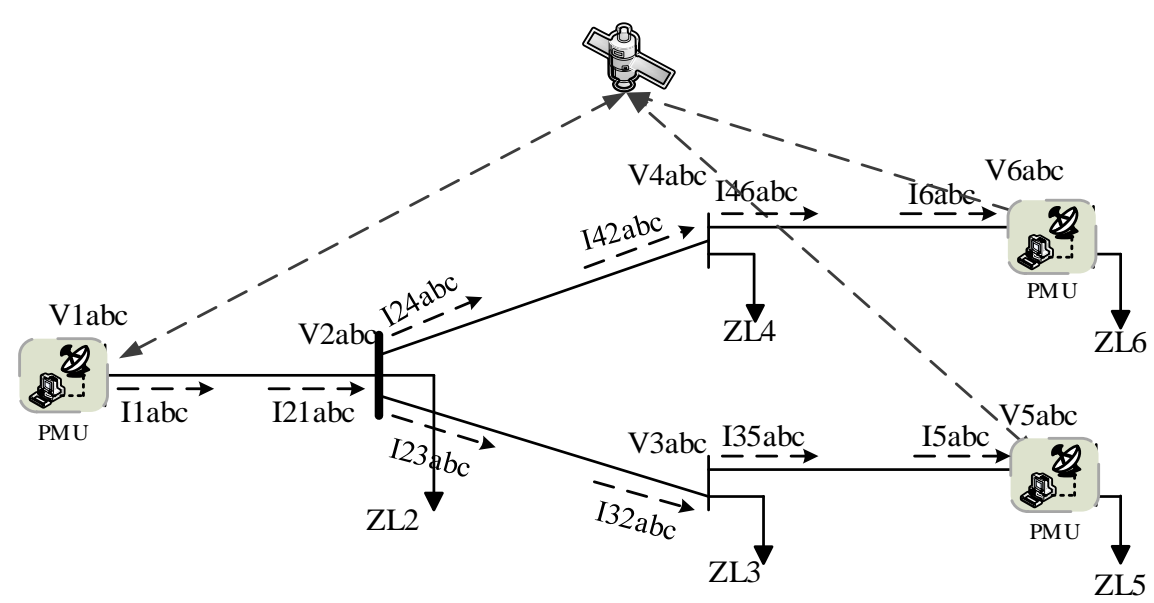

Figure 6. A single-line diagram of a sample distribution system

Similarly, according to the proposed method for installing PMUs in each distribution system, the calculation of the voltage and current of buses with the algorithm presented in this subsection is generalizable. In the event of a fault in the network, voltages and currents are also calculated, except that symmetric components are used for observation.

\subsection{Fault Location Algorithm}

The proposed fault location algorithm is presented as follows

a. The synchronous data are received from all PMUs in a cycle.

b. The calculation of the voltage and current of buses of the entire distribution system according to the algorithm provided in section 3.2 (estimation of voltage and current of all the pairs of buses at any time)

c. Equation 6 should be checked for all pairs of buses. Pair of buses in which Equation 6 does not hold are considered as sections with fault. (Go to the next step). If Equation 6 holds for all pairs of buses, go to step1.

d. According to Equations 7 to 11 and using Newton-Raphson's algorithm, fault location in line unit length (D) is estimated for all pairs of buses that are considered as the section with fault.

e. Fault has occurred between two buses where $0<\mathrm{D}<1$ and $\mathrm{D}$ is the fault location per line length unit.

f. The voltage and current of fault point $I_{\text {Fabc }}, V_{\text {Fabc }}$ are estimated according to the equations (13) to (17). The type of fault and fault resistance can be determined according to sections 2.2.1 and 2.2.2. The algorithm flowchart is shown in Figure 7.

Permanent Fault Location in Distribution System Using Phasor Measurement Units (PMU)... (Ali Khaleghi) 


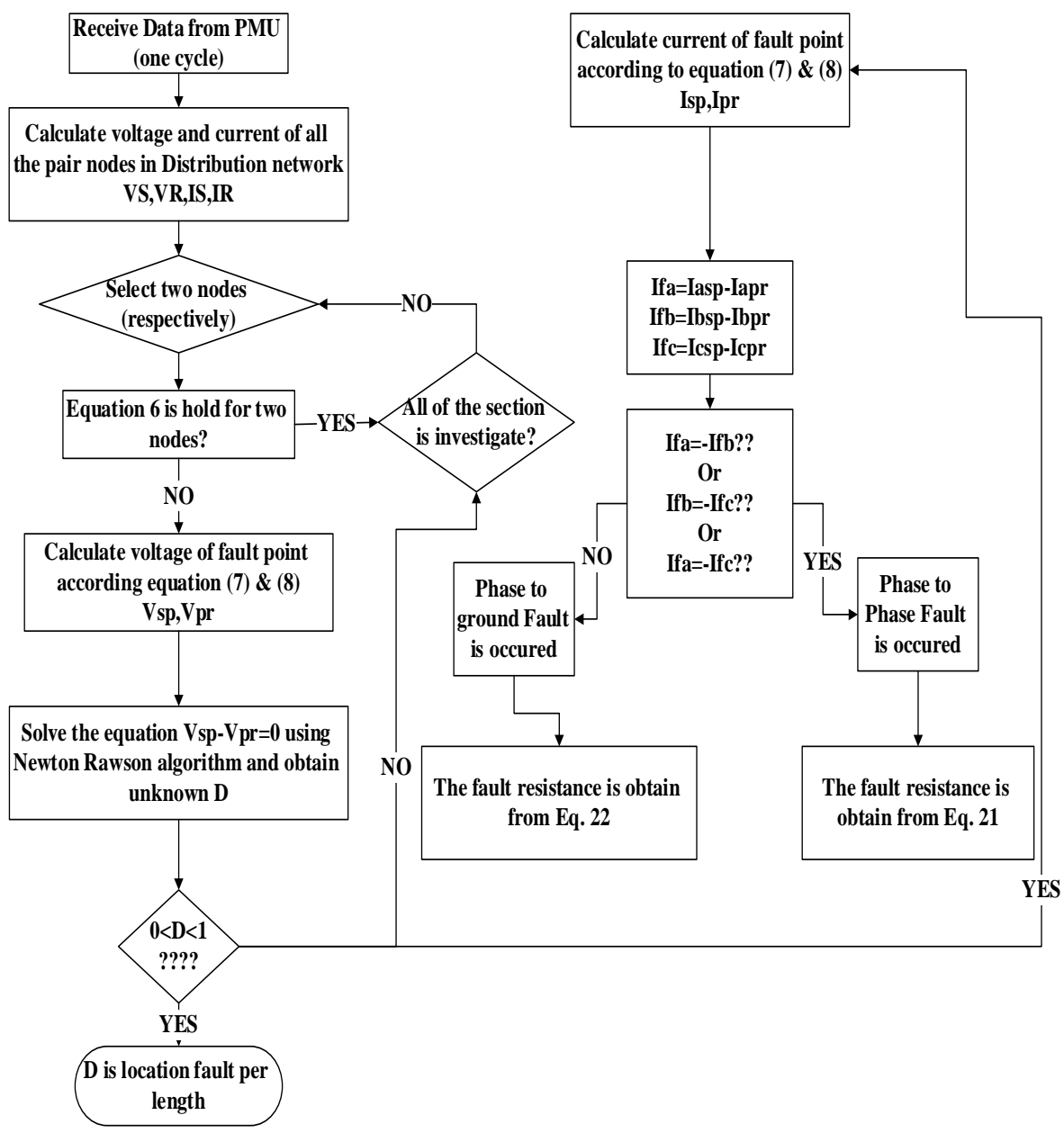

Figure 7. Flowchart of proposed method

\section{SIMULATION RESULTS AND ANALYSIS}

To evaluate the proposed method using a real system, $25 \mathrm{kV}$ distribution system of Saskpower in Canada [21] was studied. The $25 \mathrm{kV}$ single-line diagram is shown in Figure 8. The implementation of the proposed algorithms was done in MATLAB and then the simulation of $25 \mathrm{KV}$ distribution system was carry out by EMTP-RV software. In the conducted simulations, distributed line parameter model was used. All loads were considered as static load. The percentage of error in fault locating is obtained from the following equation:

$$
\text { percentage of error }=\frac{\text { actual fault location-estimate fault location }}{\text { length of line }} 100
$$




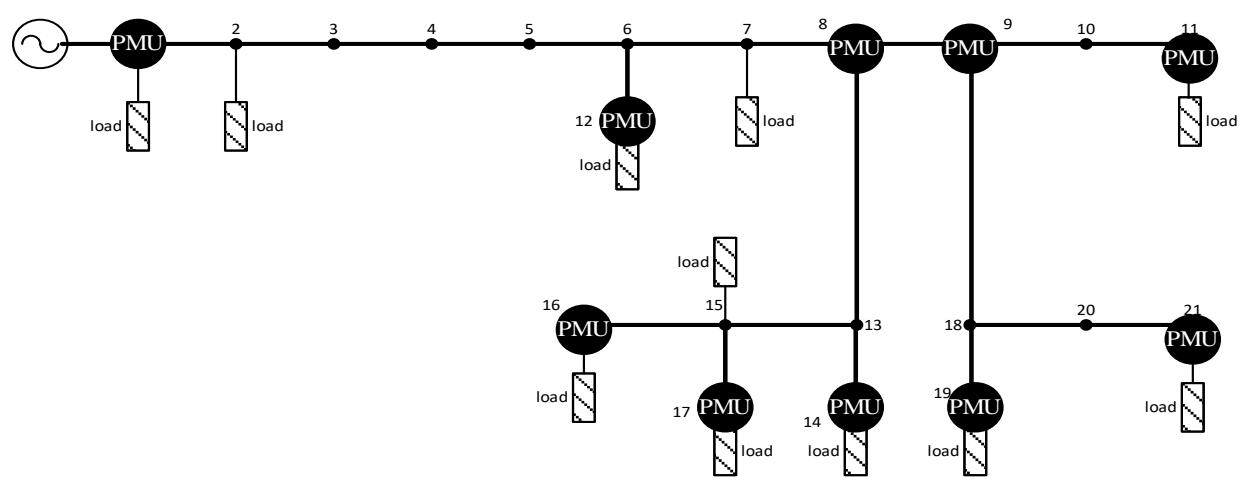

Figure 8. Diagram of $25 \mathrm{kV}$ power distribution system of Canada

Various simulations for three different pairs of buses with different types of faults (single-phase to ground, phase to phase, 3-phase to ground) were done on the $25 \mathrm{kV}$ distribution system. The results of the implementation of the proposed method are shown in Table 1. It should be noted that the line between buses (3-4) and (6-13) is three-phase, and the line between buses (18-20) is single-phase.

To demonstrate the effectiveness of the proposed method for faults with low fault impedances, faults with $10 \mathrm{ohms}$ of resistance were simulated, and the proposed method in these cases were evaluated, and the results are shown in Table 1 . In this table, in addition to the fault location estimation, the fault resistance was also estimated. The results show the high accuracy of the proposed method.

As shown in Table 1, fault locating is implemented between three pairs of buses in Canada $25 \mathrm{KV}$ distribution system. Faults have occurred at three distinct distances between two buses. In order to demonstrate the efficiency of the proposed method in various fault resistances, faults have been investigated in three distinct fault resistances (10, 100 and $300 \mathrm{ohms})$. The maximum error rate in the fault location is less than $0.15 \%$, which indicates the high accuracy of the proposed method. Also, regard to the numbers obtained in different conditions, it can be concluded that the accuracy of the method does not depend on the fault conditions and the results indicate the low sensitivity of the proposed method toward the fault resistance, fault location, and fault inception. Figure 9 to 10 shows fault percentage of error in relation to the fault resistance of 10, 100 and 300 ohms. As shown in figures, fault locating for each position in different fault resistance is close to each other.

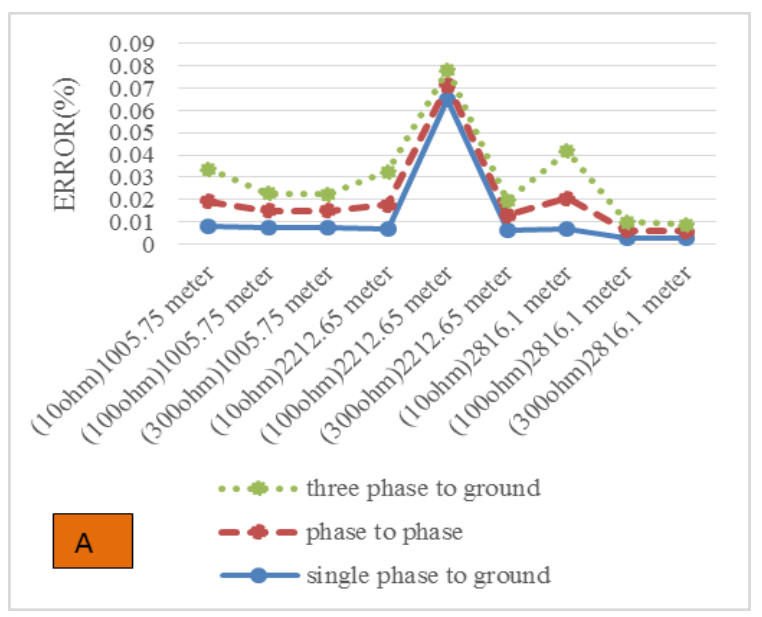

(a)

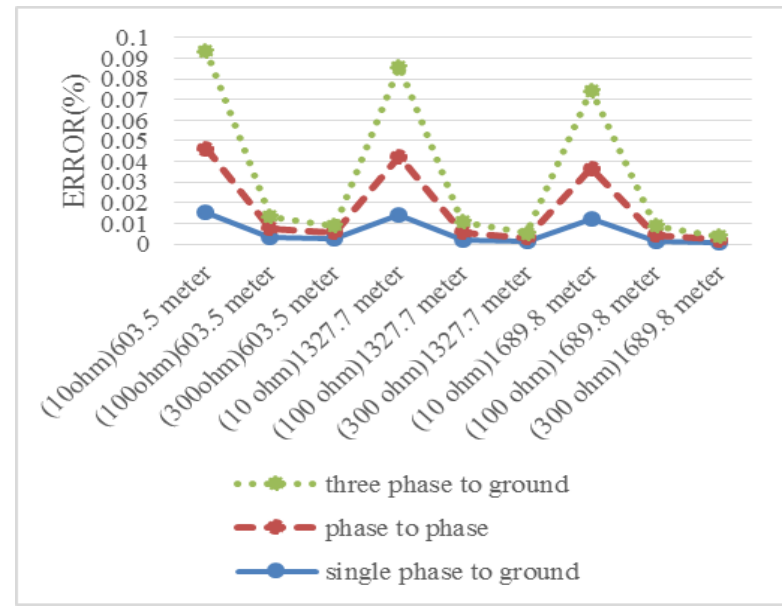

(b)

Figure 9. (a) Percentage of error between bus 3 and 4 considering different conditions. (b) Percentage of error between bus 6 and 13 considering different condition 


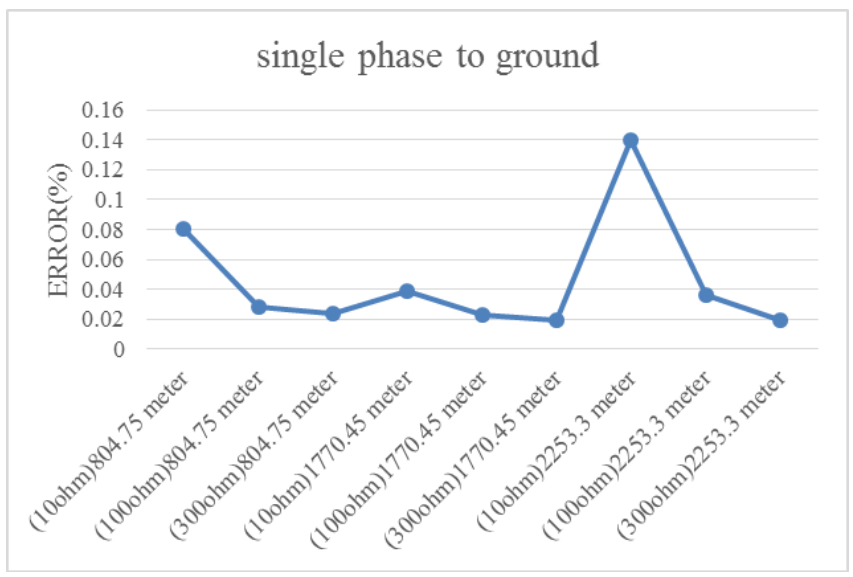

Figure 10. Percentage of error between bus 18 and 20 considering different conditions

Table 1. Simulation Results

\begin{tabular}{|c|c|c|c|c|c|c|c|}
\hline \multirow{3}{*}{$\begin{array}{c}\begin{array}{c}\text { Fault } \\
\text { resistance }\end{array} \\
\text { Fault } \\
\text { between Bus } \\
(3-4)\end{array}$} & \multirow{3}{*}{$\begin{array}{c}\text { Actual fault } \\
\text { location } \\
\text { Fault } \\
\text { Location } \\
\text { from Bus } 3\end{array}$} & \multicolumn{6}{|c|}{ Type of fault } \\
\hline & & \multicolumn{2}{|c|}{ Single phase to ground } & \multicolumn{2}{|c|}{ Phase to phase } & \multicolumn{2}{|c|}{ Three phase to ground } \\
\hline & & $\begin{array}{c}\text { Percentage of } \\
\text { Error } \\
\text { (location) } \\
\end{array}$ & $\begin{array}{c}\text { Fault } \\
\text { Resistance } \\
\text { (ohm) } \\
\end{array}$ & $\begin{array}{c}\text { Percentage of } \\
\text { Error } \\
\text { (location) }\end{array}$ & $\begin{array}{c}\text { Fault } \\
\text { Resistance(ohm) }\end{array}$ & $\begin{array}{c}\text { Percentage of } \\
\text { Error } \\
\text { (location) }\end{array}$ & $\begin{array}{c}\text { Fault } \\
\text { Resistance } \\
\text { (ohm) }\end{array}$ \\
\hline 10 ohm & & 0.0082190 & 9.9861 & 0.01094 & 10.0134 & 0.01456 & 9.9921 \\
\hline 100 ohm & $1005 . \% 5$ & 0.0074577 & 100.0379 & 0.007523 & 100.0685 & 0.007612 & 100.052 \\
\hline 300 ohm & & 0.0074354 & 300.178 & 0.007487 & 300.2094 & 0.007462 & 300.1934 \\
\hline $10 \mathrm{ohm}$ & & 0.0070608 & 9.9868 & 0.01047 & 10.0069 & 0.015064 & 9.9924 \\
\hline 100 ohm & & 0.065043 & 100.016 & 0.006545 & 100.0382 & 0.006605 & 100.0279 \\
\hline 300 ohm & meter & 0.006525 & 300.1001 & 0.006526 & 300.1224 & 0.00652 & 300.1126 \\
\hline 10 ohm & & 0.006896 & 9.9896 & 0.01363 & 10.0042 & 0.02107 & 9.994 \\
\hline 100 ohm & 2816.1 & 0.0029392 & 100.0084 & 0.0032659 & 100.0245 & 0.003713 & 100.0175 \\
\hline 300 ohm & meter & 0.0028556 & 300.0644 & 0.002908 & 300.0806 & 0.002971 & 300.0739 \\
\hline 10 ohm & & 0.015352 & 10 & 0.031029 & 10 & 0.047291 & 10 \\
\hline $100 \mathrm{ohm}$ & 603.5 & 0.0031594 & 100.0002 & 0.0043964 & 100.0002 & 0.0059012 & 100.001 \\
\hline 300 ohm & meter & 0.0026904 & 300.0006 & 0.0028942 & 300.0006 & 0.0031919 & 300.003 \\
\hline 10 ohm & & 0.014013 & 10 & 0.028465 & 10.0001 & 0.043621 & 9.9999 \\
\hline 100 ohm & $\begin{array}{l}1321.1 \\
\text { meter }\end{array}$ & 0.0021049 & 100.0001 & 0.0035189 & 100.0006 & 0.0050663 & 100.0001 \\
\hline 300 ohm & meter & 0.0014482 & 300.0003 & 0.0017519 & 300.0004 & 0.0021499 & 300.0004 \\
\hline 10 ohm & & 0.012104 & 10 & 0.024591 & 10.0001 & 0.037811 & 10 \\
\hline 100 ohm & $\begin{array}{l}1689.8 \\
\text { meter }\end{array}$ & 0.0015841 & 100.0001 & 0.0029080 & 100.0004 & 0.0042982 & 100.0004 \\
\hline 300 ohm & meter & 0.00087521 & 300.0002 & 0.0012204 & 300.0012 & 0.0016305 & 300.0012 \\
\hline 10 ohm & & 0.080157 & 10.1206 & - & - & - & - \\
\hline $100 \mathrm{ohm}$ & 804./5 & 0.028213 & 107.1013 & & & & \\
\hline 300 ohm & neter & 0.023404 & 298.0522 & - & - & - & - \\
\hline 10 ohm & & 0.038865 & 9.998 & & & & \\
\hline 100 ohm & $\begin{array}{c}17 / 0.45 \\
\text { meter }\end{array}$ & 0.022889 & 99.7842 & - & - & - & - \\
\hline 300 ohm & & 0.01899 & 298.1764 & & & & \\
\hline 10 ohm & & 0.14 & 9.9981 & - & - & - & - \\
\hline 100 ohm & $\begin{array}{l}2253.3 \\
\text { meter }\end{array}$ & 0.035857 & 99.7856 & & & & \\
\hline 300 ohm & & 0.019663 & 298.1952 & - & - & - & - \\
\hline
\end{tabular}

In order to validate the performance of the proposed method, Table 2 examines the error rate in the fault locating in distribution systems with different methods. As shown in table 2, the method presented in this paper has a relative superiority to other methods.

Table 2. Comparison between Different Methods

\begin{tabular}{ccccc}
\hline \multicolumn{5}{c}{ Mean of error (\%) } \\
\hline Fault type & Proposed method & $\begin{array}{c}\text { Ref [24] } \\
\text { Fault res. (10ohm) }\end{array}$ & $\begin{array}{c}\text { Ref [25] } \\
\text { Fault res. (10 ohm) }\end{array}$ & $\begin{array}{c}\text { Ref [26] } \\
\text { Fault res. (100ohm) }\end{array}$ \\
\hline Single phase to ground & 0.021 & - & 2.293 & 1 \\
Phase to phase & 0.009 & 0.065 & - & - \\
Three phase & 0.013 & 0.085 & 2.294 & - \\
\hline
\end{tabular}




\section{CONCLUSION}

Finding a fast and accurate fault locating method has been of particular importance. In the meantime, it should be considered that the location of the fault in the distribution system is more complex than the transmission system. Due to the increasing use of PMUs in power systems for network monitoring, in this article, the PMUs have been used to provide a method for fault locating. In the proposed method, first, according to the system topology, the location of the installation of the PMUs should be located so that the data of all buses can be calculated from both sides during the faults. If a fault occurs in the system, the information obtained from both sides of a bus is not consistent with each other. Subsequently, based on the proposed algorithm the fault location and type will be estimated. In the proposed method, according to the characteristics of the PMUs, the asymmetry and the presence of several laterals in lines, in the fault locating are ineffective. The maximum percentage of fault locating error is less than $0.15 \%$, indicating the high accuracy of the proposed method. The results also showed the low sensitivity of the proposed method to resistance, location and type of the faults. Also, the evaluation of the proposed method and comparison with other previous work on fault locating in distribution systems indicates the superiority of the proposed method.

\section{REFERENCES}

[1] M. Daisy, R. Dashti. "Single phase fault location in electrical distribution feeder using hybrid method”, Energy, vol. 103, pp. 356-68, 2016.

[2] S. Jamali, A. Bahmanyar, “A new fault location method for distribution networks using sparse measurements”, Int. J. Electr. Power Energy Syst. Vol. 81, pp. 459-468, 2016

[3] W. Jianmin, S. Weiwei, C. Yanping, J. Xin, S. Jidong, and W. Dongju, "Study on Locating Techniques of Singlephase Grounding Fault in Distribution Network”, TELKOMNIKA Indonesian Journal of Electrical Engineering, Vol. 12, no. 3, pp. 1701-1707, 2014.

[4] Chen Xu, Yin Xianggen, Deng Shanfei, et al. "Novel method for SLG fault location in power distribution system using time lag of travelling wave components” IEEJ Transactions on Electrical and Electronic Engineering, vol. 12, pp. 45-54, 2017.

[5] X. Yang, M.S. Choi, S.J. Lee, C.W. Ten, and S.I. Lim, "Fault Location for Underground Power Cable Using Distributed Parameter Approach,” IEEE Transactions on Power Systems, vol. 23, no. 4, pp. 1809-1816, 2008.

[6] A. Bahmanyar, A. Estebsari, E. Pons, S. Jamali, E. Bompard, "An improved fault location method for distribution networks exploiting emerging LV smart meters”, IEEE Workshop on Environmental, Energy, and Structural Monitoring Systems(EESMS), Bari, pp.1-6. 2016

[7] B.D. Russel, C.L. Benner, and A.V. Mamishev, “Analysis of High Impedance Fault Using Fractal Techniques,” IEEE Transaction Power System, vol. 11, pp. 435-440, Feb. 1996.

[8] M. Sarvi, "Determination of Fault Location and Type in Distribution Systems using Clark Transformation and Neural Network”, International Journal of Applied Power Engineering (IJAPE), vol. 1, no. 2, pp. 75-86, 2012.

[9] M. Michalik, M. Łukowicz, W. Rebizant, S.-J. Lee, and S.-H. Kang, "New ANN-Based Algorithms for Detecting HIFs in Multigrounded MV Networks,” IEEE Transactions on Power Delivery, vol. 23, no. 1, Jan. 2008.

[10] M. Michalik, W. Rebizant, M. Łukowicz, S.-J. Lee, and S.-H. Kang, "High-Impedance Fault Detection in Distribution Networks With Use of Wavelet-Based Algorithm,” IEEE Transactions on Power Delivery, vol. 21, no. 4, Oct. 2006.

[11] A.H.A. Bakar, M.S. Ali, C. Tan, H. Mokhlis, H. Arof, and H.A. Illias, "High Impedance Fault Location in $11 \mathrm{kV}$ Underground Distribution Systems Using Wavelet Transforms,” Electrical Power and Energy Systems, vol. 55, pp. 723-730, 2014.

[12] M. Zahri, Y. Menchafou, H. Markhi, M. Habibi, "Simplified Method for Single Line to GroundFault Location in Electrical Power Distribution Systems”, International Journal of Electrical and Computer Engineering (IJECE), Vol. 5 No. 2, pp. 221-230, 2015.

[13] M. Majidi, A. Arabali, M. Etezadi-Amoli, "Fault location in distribution networks by compressive sensing”, IEEE Trans. Power Deliv. Vol. 30, pp. 1761-1769, 2015.

[14] F. V. Lopes. "Settings-free travelling-wave-based earth fault using unsynchronized two-terminal data" IEEE Transactions on Power Delivery, vol. 31, no. 5, pp. 2296-8, 2016.

[15] S. Chakrabarti, and E. Kyriakides. "Optimal placement of phasor measurement units for observability," IEEE Transaction Power System, vol. 23, no. 3, pp. 1433-1440. 2008.

[16] C. Muscas, F. Pilo, G. Pisano, and S. Sulis, "Optimal Placement of Multichannel Measurement Devices in Electric Distribution Systems,” IEEE Transactions on Instrumentation and Measurement, vol 58, no. 6, pp. 1929-1937, Jun. 2009.

[17] A. Borghetti, C. A. Nucci, M. Paolone, G. Ciappi, and A. Solari, "Synchronized Phasors Monitoring During the Islanding Maneuver of an Active Distribution Network,” IEEE Transaction on Smart grid, vol. 2, no. 1, pp. 82-91, 2011.

[18] A.A.P. Biscaro, R.A.F. Pereira, and J.R.S. Mantovani, "Optimal Phasor Measurement Units Placement for Fault Location on Overhead Electric Power Distribution Feeders,” IEEE/PES Transmission and Distribution Conference and Exposition, Latin America, PP. 37-43, 2010. 
[19] C. Wang, C.-X. Dou, X.-B. Li, and Q.-Q. Jia, “A WAMS/PMU-Based Fault Location Technique,” Electric Power Systems Research, vol. 77, pp. 936-945, 2007.

[20] A.H. Al-Mohammeda, and M.A. Abidoa, "An Adaptive Fault Location Algorithm for Power System Networks Based on Synchrophasor Measurements,” Electric Power Systems Research, vol. 108, pp. 153- 163, 2014.

[21] J. Mora-Florez, J. Melendez, and G. Carrillo-Caicedo, "Comparison of Impedance Based Fault Location Methods for Power Distribution Systems,” Electric Power Systems Research, vol. 78, no. 4, pp. 657-666, 2008.

[22] S. Mandava, J. Vanishree, V. Ramesh, "A Spanning Tree Approach in Placing Multichannel and Minimum Channel PMU's for Power System Observability”, International Journal of Electrical and Computer Engineering (IJECE), vol. 5, No. 3, pp. 518-524, 2015.

[23] F. Aminifar, M. Fotuhi-Firuzabad, M. Shahidehpour, and A. Safdarian, "Impact of WAMS Malfunction on Power System Reliability Assessment,” IEEE Transaction Smart grid, vol. 3, no. 3, Sep. 2012.

[24] W. Xiu, and Y. Liao, "Novel fault location methods for ungrounded radial distribution systems using measurements at substation,” Electric Power Systems Research vol. 106, pp.95- 100, 2014.

[25] A. D. Filomena, M. Resener, R. H. Salim, and A. S. Bretas, "Fault location for underground distribution feeders: An extended impedance-based formulation with capacitive current compensation,” Electric Power Systems Research vol. 31, pp.489- 496, 2009.

[26] J. Ren, S. S. Venkata, and E. Sortomme, “An Accurate Synchrophasor Based Fault Location Method for Emerging Distribution Systems,” IEEE Transaction on Power Delivery, vol. 29, no. 1, pp. 297-298, 2014.

\section{BIOGRAPHIES OF AUTHORS}
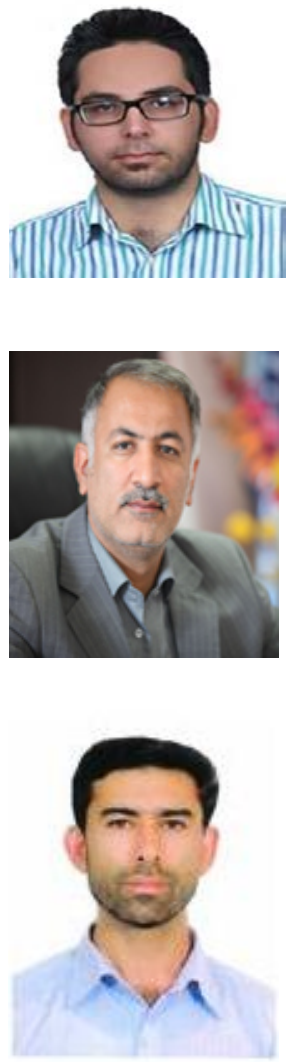

Ali Khaleghi was born in 1989 in Kerman, Iran. He obtained his B.Sc. in Electrical Engineering in 2012 at Shahid Bahonar University, Kerman, Iran. He received his M.Sc. degree in Electrical and Electronic Engineering from the University of Sistan and Baluchestan, Zahedan, Iran in 2015. His research interests include Power System Protection, intelligent system, and control system.

Mahmoud Oukati Sadegh was born in 1966 in Zabol, Iran. He received the B.Sc. and M.Sc. degree in electrical power system engineering from Tehran University, Tehran, Iran, in 1989 and 1992 respectively. the Ph.D. degree in electrical engineering from Strathclyde University in Glasgow, UK in 2003. Currently, he is an Assistant Professor in the Department of Electrical and Electronic Engineering, University of Sistan and Baluchestan, Zahedan, Iran. His research interests are power system control and operation, Electrical distribution system and Smart grid.

Mahdi Ghazizadeh Ahsaee, received the B.Sc. degree in electronic engineering from Bahonar University of Kerman, Kerman, Iran, in 2000, the M.Sc. degree in electrical engineering from Mazandaran University, Babol, Iran, in 2003, and the Ph.D. degree in electrical engineering from Ferdowsi University of Mashhad, Mashhad, Iran, in 2012. Currently, he is an Assistant Professor in the Department of Electrical Engineering, University of Zabol, Zabol, Iran. His research interests are power system protection, fault location, and application of flexible ac transmission systems devices. 